\title{
Research methods in the study of heat transfer coefficient during flow in minichannels
}

\author{
Maria TYCHANICZ-KWIECIEŃ, Sebastian GROSICKI
}

DOI: $10.30464 /$ jmee.2021.5.1.59

Cite this article as:

Tychanicz-Kwiecień M., Grosicki S. Research methods in the study of heat transfer coefficient during flow in minichannels. Journal of Mechanical and Energy Engineering, Vol. 5(45), No. 1, 2021, pp. 59-68.

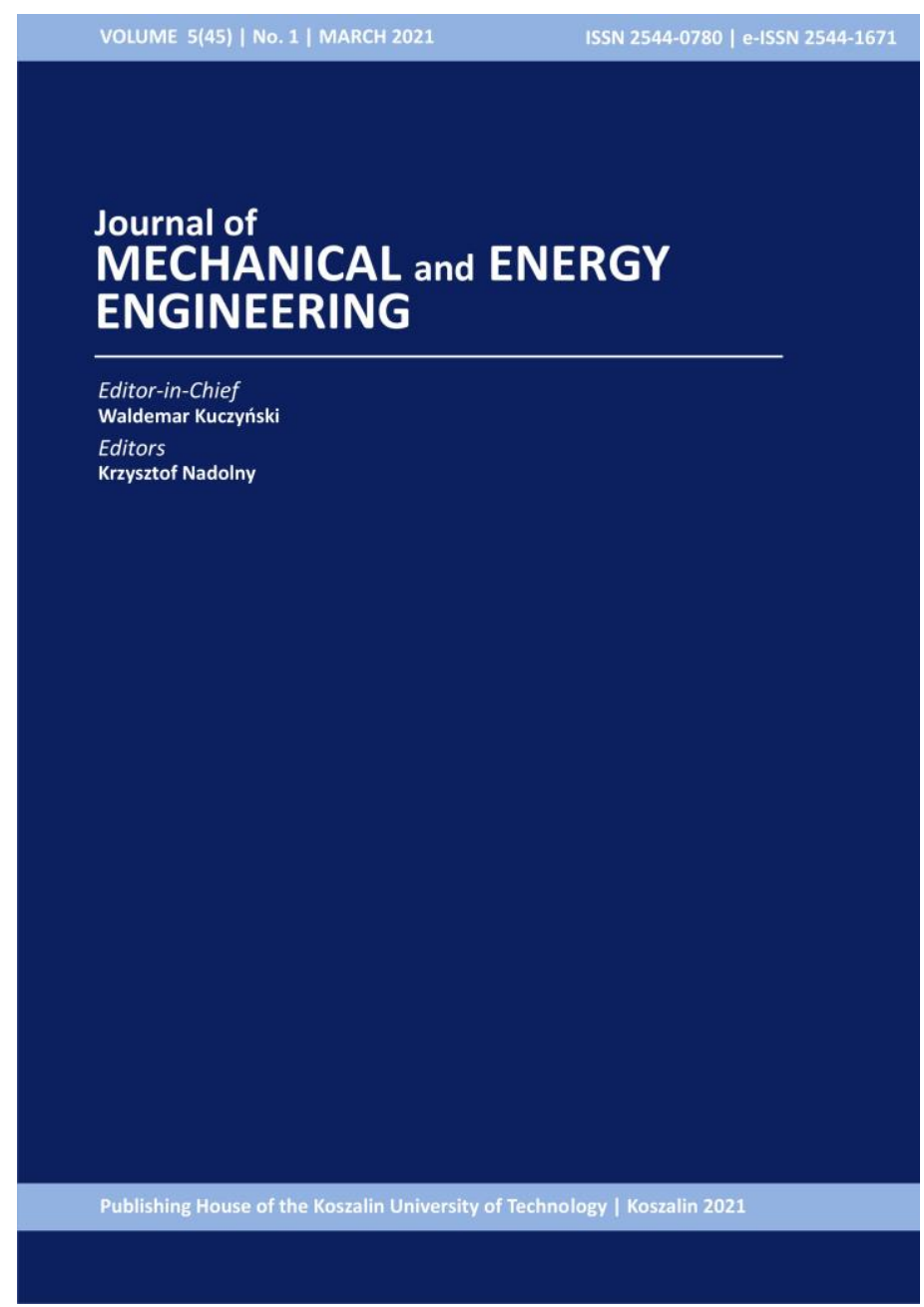

\section{Journal of Mechanical and Energy Engineering}

Website: jmee.tu.koszalin.pl

ISSN (Print): 2544-0780

ISSN (Online): 2544-1671

Volume: 5(45)

Number: 1

Year: 2021

Pages: 59-68

Article Info:

Received 3 March 2021

Accepted 25 March 2021

\section{Open Access}

This article is distributed under the terms of the Creative Commons Attribution 4.0 (CC BY 4.0) International License (http://creativecommons.org/licenses/by/4.0/), which permits unrestricted use, distribution, and reproduction in any medium, provided you give appropriate credit to the original author(s) and the source, provide a link to the Creative Commons license, and indicate if changes were made. 


\title{
RESEARCH METHODS IN THE STUDY OF HEAT TRANSFER COEFFICIENT DURING FLOW IN MINICHANNELS
}

\author{
Maria TYCHANICZ-KWIECIEN' ${ }^{1}$, Sebastian GROSICKI ${ }^{1 *}$ \\ 1* The Faculty of Mechanical Engineering and Aeronautics, Department of Thermodynamics, Rzeszów \\ University of Technology, al. Powstańców Warszawy 8, 35-959 Rzeszów, Poland \\ e-mail: sebogr@prz.edu.pl
}

(Received 3 March 2021, Accepted 25 March 2021)

\begin{abstract}
The paper presents the specification of research methods commonly encountered in the studies of heat transfer processes in minichannels. In particular the following methods have been emphasized: electrochemical limiting current method as well as the thermal balance method. In thermal balance method the mean heat transfer coefficient is determined by the set of experimental thermal measurements of the investigated heat exchanger. In turn, limiting current method is based on heat and mass transfer analogy. The discussed research methods have been implemented on two specially designed and constructed test facilities with compact minichannel heat exchangers, which have been presented and described in details. In order to validate the designed setup, the preliminary experimental measurements of two minichannel heat exchangers with hydraulic diameter of $2 \mathrm{~mm}$ and rectangular cross sections during single-phase liquid flows have been carried out. In further perspective it is planned to extend the experimental studies of minichannel heat exchangers and to compare the results obtained by both methods described.
\end{abstract}

Keywords: heat transfer coefficient, minichannels, heat and mass transfer analogy, limiting current technique, thermal balance method

\section{INTRODUCTION}

Miniaturization has captured various fields of application, including electronics, medicine, heat and power engineering, compact heat exchangers, industrial technology and many others. Mini- and microchannel heat exchangers are an important group of heat transfer components which cover the demand for heat reception in widespread small-scale systems. The classification of channels proposed by Kandlikar reveals that the term minichannel refers to the hydraulic diameter within the range of $200 \mu \mathrm{m} \leq$ $d_{h} \leq 3 \mathrm{~mm}$. Channels with hydraulic diameter $d_{h} \leq$ $200 \mu \mathrm{m}$ are classified as microchannels. Throughout the years an extensive studies concerning heat transfer and fluid flow in minichannels have been carried out. A brief overview of selected literature on heat transfer and flow in minichannels have been presented below.

Owhaib et all [1] studied experimentally heat transfer characteristics of single-phase forced convection of R134a in single circular micro-channels of various inner diameters. The obtained results were compared to correlations for the heat transfer applicable in macroscale channels and to correlations suggested for microscale geometries.

In [2] the experimental investigation of turbulent, single-phase forced convection of water in circular microchannels has been presented. Based on the results obtained, a generalized Nusselt number correlation has been proposed.

Lelea et all [3] studied experimentally and numerically the heat transfer and fluid flow in circular microchannels in order to compare the experimentally obtained thermal and flow characteristics with numerical and theoretical results appropriate for conventional channels.

The experimental investigation of forced convective heat transfer performance during flow of water in several microtubes have been presented in [4]. The study provides the verification of application of conventional heat transfer correlations for laminar and turbulent flow to fully developed heat transfer performance in microtubes. 
In [5], an experimental investigation of singlephase laminar flow in circular microducts has been reported. The influence of scaling effects on heat transfer has been analyzed.

From the reported studies it was found that the application of classical theory of heat transfer and fluid flow in ducts to minichannel systems often leads to significant discrepancies between experimental data and theoretical predictions. Unlike in conventional channels, the analysis of thermal and hydraulic performance in mini-scale requires the consideration of many factors, like the channel shape and cross section, channel surface roughness, the shape and arrangement of the inlet and outlet manifold, axial heat conduction in the channel walls as well as operating parameters of working media (i.e. temperature, volumetric flow rate, density, thermophysical properties etc.) and many others, which could be ignored in the analysis of regular-size heat exchangers. Therefore, from the viewpoint of various factors that should be included, the analysis of heat transfer processes during flow in small diameter channels is a challenging task. A key issue at the design stage is to obtain the optimal dependency between desired heat transfer enhancement and pressure drop.

In the context of convective heat transfer, the basic thermal parameter is the heat transfer coefficient, which characterizes the heat transfer between solid body and surrounded fluid. This parameter also plays an important role in the proper design of heat exchangers exposed to high heat loads. According to the definition, heat transfer coefficient depends on the heat flux and the temperature difference between the solid surface and mean fluid bulk temperature.

The thermal and flow characteristics in minichannels can be determined by various methods. The significance of experimental approach in general heat transfer problems is undisputed. Therefore, as far as experimental methods are concerned, the investigation of heat transfer during flow in minichannels can be accomplished with the use of thermal balance method due to simplicity and convenience. The thermal balance method is classical and well known technique and has been applied in numerous experimental studies described in scientific literature [1-5]. In general, the method is based on the comparison of heat released and heat absorbed by bodies in an thermally insulated system, i.e. which does not exchange heat with the environment.

The thermal balance method allows the direct determination of heat exchangers thermal characteristics on the basis of experimental measurements. However the method is not devoid of restrictions regarding the measurements in small diameter channels. In many practical cases the experimental measurements of basic thermal parameters in minichannels are troublesome or even impossible [6]. In particular, the problem is related to the temperature or heat flux measurement difficulties inside small diameter channels, especially of complex geometries. In order to exclude the inner temperature measurements, the limiting current method can be used to determine the thermal performance of heat exchangers [7].

The limiting current method, which is also known as electrolytic technique, is used to obtain mass transfer coefficients and corresponding heat transfer coefficients are determined from correlations describing the analogy between mass and heat transfer processes [8]. Following the laws applicable in electrochemistry, the proper equations can be derived and therefore mass transfer coefficients can be determined. When applied to minichannels, the limiting current method requires the consideration of some factors which arise from so called scaling effects and which results from the specific of the method, e.g. the roughness effects, the variation of the ion concentration, mean thickness diffusion layer [8]. Although there is not many comprehensive literature studies concerning the limiting current method, the application of the method to investigate the mass transfer in minichannels [7-9] including the nanofluid flows have been discussed.

Apart from the aforementioned methods, the special attention should be also paid to statistical determination of experimental thermal and hydraulic characteristics of heat exchangers, which could complement or extend the results obtained by thermal balance method. The Wilson plot technique, which belongs to this group, enables the indirect determination of heat transfer coefficients without the experimental measurement of the channel wall temperature. In the original Wilson method only the series of experimental measurements of inlet and outlet fluid temperatures and flow rates are required. Wilson method was originally applied to shell and tube heat exchanger. Over the years the Wilson plot method has undergo series of modifications in order to extend its application to more sophisticated heat exchanger design and enhanced flow conditions. More detailed information concerning the application of both the original and modified Wilson plot method in various heat transfer problems can be found in literature [10-15]

The aim of the paper is to present the available research methods widely applied in the investigations of heat transfer coefficient in minichannels. The main focus was put on thermal balance method and mass transfer method. The specific of the discussed methods was presented in details. In practice, both methods have been implemented on specially designed experimental laboratory test facilities, which have been described in details. In order to validate the designed setup, the preliminary experimental 
measurements of two minichannel heat exchangers with hydraulic diameter of $2 \mathrm{~mm}$ and rectangular cross sections have been carried out. The design concepts of the investigated minichannel heat exchangers were adopted to the nature of the measurements performed on each test stand. The experimental measurements have been carried out for single-phase liquid flows in both cases. In the long term, it is required to extend the range of the experimental measurements performed by both methods, including the various geometry and shapes of tested minichannel heat exchangers. Therefore, further through experimental research are planned.

\section{LIMITING CURRENT TECHNIQUE}

The analogy between heat and mass transfer processes forms the nature of model studies of heat transfer based on results obtained for mass transfer. The analogy between mass and heat transfer was developed by Schmidt and Nusselt on the basis of the conservation equations for mass and heat transfer of a fluid of constant properties. The main objective of the analogy theory is to transfer information from the mass transfer process to a geometrically and physically comparable heat transfer process and vice versa [16]. Similar terminology and mathematical models are used to describe both mass and heat transfer processes. In mass transfer the gradient of concentration of the molecules or ions exchanged under the influence of diffusion plays a fundamental role, while in heat transfer process the gradient of the fluid temperature is essential [8].

The Sherwood and Nusselt numbers are analogous terms which represent mass transfer intensity by diffusion and heat transfer intensity by convection respectively. In mass/heat transfer analogy the simplest cases of boundary conditions are taken into account. They involve the constant concentration and temperature as well as the constant mass or heat flux at the wall.

The results of experiments on mass transfer are expressed in the well-known empirical equation [9]:

$$
S h=C R e^{p} S c^{q} .
$$

According to the analogy of mass and heat transfer processes, the results for heat transfer can be expressed in the form [9]:

$$
N u=C \operatorname{Re}^{p} \operatorname{Pr}^{q} .
$$

Dimensionless numbers are given by:

$$
\begin{gathered}
N u=h \cdot d_{H} / k, S h=h_{D} \cdot d_{H} / D, \\
P r=v / a \quad S c=v / D .
\end{gathered}
$$

It is difficult to fulfil all the mass and heat transfer analogy conditions. The requirement of fluid properties similarity expressed by equal Schmidt and
Prandtl numbers is especially difficult to meet. If $S c$ and $P r$ are not equal, the ratio of equation (2) to (1) indicates that the results of the mass transfer experiment may be converted to the corresponding heat transfer formula [9]:

$$
N u / S h=(\operatorname{Pr} / S c)^{q} .
$$

The exponent $q$ is the constant determined from empirical investigations. Based on the available data, the analogy proposed by Chilton and Colburn seems to be most useful when applied in internal flow through minichannels. In the Chilton-Colburn relation, the value of the exponent $q$ was found to be $1 / 3$. One of the method which refers to the mass/heat transfer analogy, is the limiting current technique.

The limiting current method is an electrolytic technique related to mass transport in the electrode process.The limiting current technique involves observing the controlled ion diffusion at the cathode. The fundamental of the technique lies in the measurement of the limiting currents generated in the external circuit during the electrolysis process, which takes place in the electrolyte system. The surface of the cathode is an element that models the heat transfer surface area in real phenomenon. In the limiting current technique, the electrodes (cathode and anode) are immersed in the electrolyte. When an external voltage is supplied to the system, the processes of anionic reduction at the cathode and oxidation at the anode are observed.

A classical system for mass transport measurements with the use of limiting current method is a reduction of ferricyanide ions at the cathode surface and an oxidation of ferrocyanide ions at the anode. A solution of potassium or sodium hydroxide is applied as the basic electrolyte. The process of oxidation-reduction under conditions that meet the controlled diffusion is described as:

$$
\mathrm{Fe}(\mathrm{CN})_{6}^{-4} \stackrel{\text { ox red }}{\longleftrightarrow} \mathrm{Fe}(\mathrm{CN})_{6}^{-3}+e .
$$

The increase in voltage causes an increase in the intensity of the electric current flowing in the external circuit until the so-called controlled diffusion occurs; then the concentration of working ions at the cathode decreases to zero and the current intensity reaches a constant value (limiting current). An appearing electric current is proportional to the ions reacting at the electrode per unit time [8].

The magnitude of the generated current is given by the Faraday's law [17]:

$$
I=i A=n F A N .
$$

If the transport of ions by the diffusion is only taken into account, based on Fick's law and Nernst model, the equation (7) we be written as:

$$
I=n F A h_{D}\left(C_{b}-C_{w}\right) .
$$


If the surface of an anode is much greater than cathode, a further rise of the applied voltage will not increase the current intensity and the limiting current occurs. The ion concentration at the cathode surface approaches zero. Measurements of the limiting current allows to obtain the mass transfer coefficient from the following equation:

$$
h_{D}=\frac{I_{p}}{n F A C_{b}} .
$$

In order to obtain mass transfer coefficients from equation (9), the value of bulk ions concentration $C_{b}$ is requested. This value is received from the equation of mass balance in minichannel during electrochemical processes at the cathode surface being the inner surface of the minichannel [18]. This equation is as follows:

$$
C_{\text {out }} \dot{V}=C_{\text {in }} \dot{V}-C_{b} A h_{D} .
$$

The term $C_{b} A h_{D}$ represents a flux of reacting ions.

Considering the equation (10), the value of ion concentration at the minichannel outlet can be written as:

$$
C_{\text {out }}=C_{\text {in }}-I_{p} /(n F \dot{V}),
$$

where $C_{i n}$ is measured with the use of iodometric titration.

As the concentration of reacting ions varies with the length of the minichannels, the average deviation of $C_{b}$ can be calculated as:

$$
\delta C_{b}=\left(C_{\text {in }}-C_{\text {out }}\right) / C_{\text {out }} .
$$

\section{EXPERIMENTAL MASUREMENTS IN MINICHANNELS}

\subsection{Limiting current technique}

The schematic diagram of the experimental test facility designed for mini-scale electrolytic measurements is presented in Fig. 1. In the designed test facility a convection heat transfer occurs during laminar flow of the medium through the set of minichannels. The schematic design of a tested model of compact minichannel heat exchanger, which was presented in Fig. 2, consisted of nine parallel minichannels with a square cross section. The hydraulic diameter of the channels was equal to $2 \mathrm{~mm}$ (it was a side of the square) and the channel length was $100 \mathrm{~mm}$. The model has been made of $2 \mathrm{~mm}$ thick nickel sheet. The inner surface of minichannels has been working as the cathode at which electrochemical processes responsible for the mass transfer occur during the limiting current measurements. The main part of the test stand is the test section, in which the investigated heat exchanger was mounted as well as the anode.

The facility ensures the step alternation and measurement of the external voltage applied to the electrodes and measurement of the electric current in the external circuit. Nitrogen is supplied to the system in order to remove dissolved oxygen from the electrolyte.

The measurements of electrolyte flow rate are performed with the use of constriction flowmeters. The temperature of the electrolyte is controlled by calibration bath due to the necessity of maintaining the stability of the electrolyte thermophysical properties. The control of the current voltage in the electrical system and the recording of the voltage-current characteristics (voltamograms) is carried out automatically by using a multimeter which enables the data recording and processing.

The limiting current was resulting only from the process described by equation (9). This way the unwanted reaction of reduction at the cathode has been eliminated. The proper condition of the electrode surfaces has been provided by the polishing with the use of greasy diamond abrasive compound. The polishing of electrode surfaces, in particular the cathode surface, has reduced the surface roughness and simultaneously, the accuracy of the cathode surface determination has been increased. Additional conditions that must be met for proper measurements are the adequate time for electrolyte preparation and the protection of the electrolyte from sunlight. Because the concentration of ferricyanide ions changes over time, the electrolyte has been freshly prepared before each series of measurements. The decomposition in concentration of the reacting ions occurring under direct sunlight has been minimalized due to the application of the opaque elements of the experimental facility.

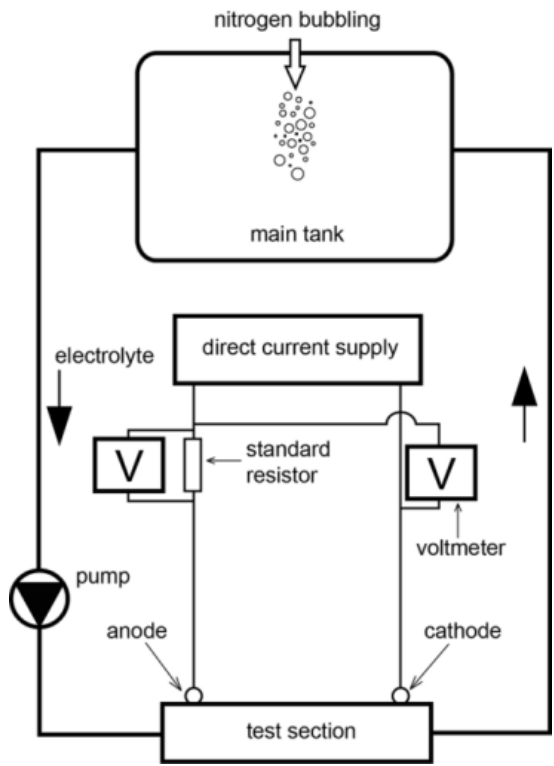

Fig. 1. The schematic diagram of the electrolytic test facility operating in a closed loop; the direction of the electrolyte flow is marked 


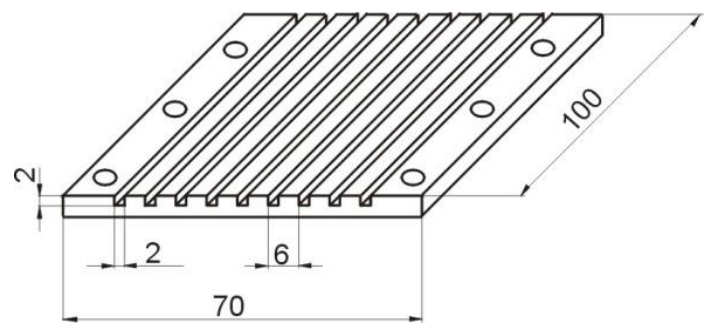

Fig. 2. The tested model of a compact minichannel heat exchanger designed for electrolytic measurements

\subsection{Thermal balance method}

The experimental facility presented schematically in Fig. 3 provides the possibility of obtaining the heat transfer rate of investigated heat exchanger during single-phase water flows. The discussed test stand allows the measurements of both conventional and mini-heat exchangers. The measurements are carried out in steady-state conditions. The basic equipment of the presented experimental unit is the investigated test section with minichannel heat exchanger placed in an insulation (polystyrene box filled with fragmented polystyrene), thermocouple set to measure inlet and outlet fluid temperatures, automatic ice point reference for the stabilization of the thermocouple cold junction, pressure transducers, which measure pressure drop across the test section and constant temperature baths for hot and cold sides of the heat exchanger. Distilled water in hot and cold side flows in counter-flow arrangement and circulates in a closed loop. Both circulating baths are equipped with refrigerating and heating modules and two-speed pressure circulator pumps and provide precise temperature control within the range of $-30^{\circ} \mathrm{C}$ to $150^{\circ} \mathrm{C}$. Flow meters on both sides are located on the outflow of the heat exchanger. The fluid temperature at the inlet and outlet of the heat exchanger is measured by the set of K-type thermocouples. All measuring equipment, including pressure transducers, thermocouples and flow meters, have been calibrated before the test loop was constructed. The specification of each measuring equipment as well as the calibration procedures and obtained results have been presented and described in detail in [19]. The measurement accuracy of each device was presented in Table 1 .

The data registration and acquisition process has been fully automated by using the National Instrument software. The electrical signals from thermocouples, pressure transducers and flow meters have been registered by the multimeter connected to the computer, while the measurement results have been displayed in the LabVIEW dialog box and the data were saved as text files. The proper measurement preparation requires prior activation of air conditioning, the multimeter and ice point temperature unit.
Heat transfer rate of particular side of the heat exchanger is calculated as:

$$
\dot{Q}=\dot{V}_{w} \cdot \rho\left(T_{\text {out }}\right) \cdot c_{w}\left(T_{\text {avg }}\right) \cdot\left(T_{\text {in }}-T_{\text {out }}\right) .
$$

The density of water was determined from [20] for water outlet temperature. Specific heat of water was calculated as a function of the average water temperature.

According to the Newton's law of cooling, heat transfer coefficient of investigated heat exchanger is defined as [15]:

$$
h=\frac{q^{\prime \prime}}{T_{s}-T_{\infty}} .
$$

Therefore, the wall surface temperature is required to obtain thermal characteristics of investigated heat exchanger. In the discussed test section customized to thermal balance method the channel wall temperature was not measured experimentally. Thermal characteristics of investigated minichannel heat exchanger will be determined statistically on the basis on experimental measurements of the outer parameters of heat exchanger, according to equation (13). The applied statistical method belongs to the group of Wilson plot methods.

In order to experimentally validate the constructed test facility, the preliminary thermal measurements of minichannel heat exchanger have been performed. The real view of investigated heat exchanger was presented in Fig. 4. The geometry of the minichannel test section investigated by thermal balance method was analogical to the concept developed for electrolytic measurements. More specifically, the test section have several, straight parallel channels with rectangular cross section, hydraulic diameter is equal to $2 \mathrm{~mm}$ and the channels have length of $100 \mathrm{~mm}$. The test section was made of aluminum plate in which the channels have been milled. The test section was attached to the housing on both sides with screws. The flow direction at the inlet and outlet was arranged perpendicularly towards the channels. This type of inlet and outlet orientation is commonly called the Ctype arrangement.

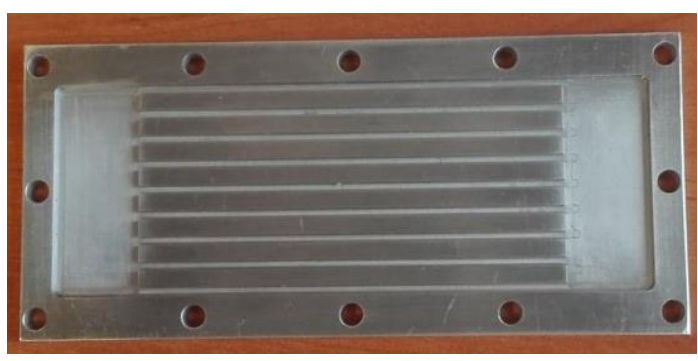

Fig. 3. The real view of a model of compact minichannel test section used in thermal balance measurements 


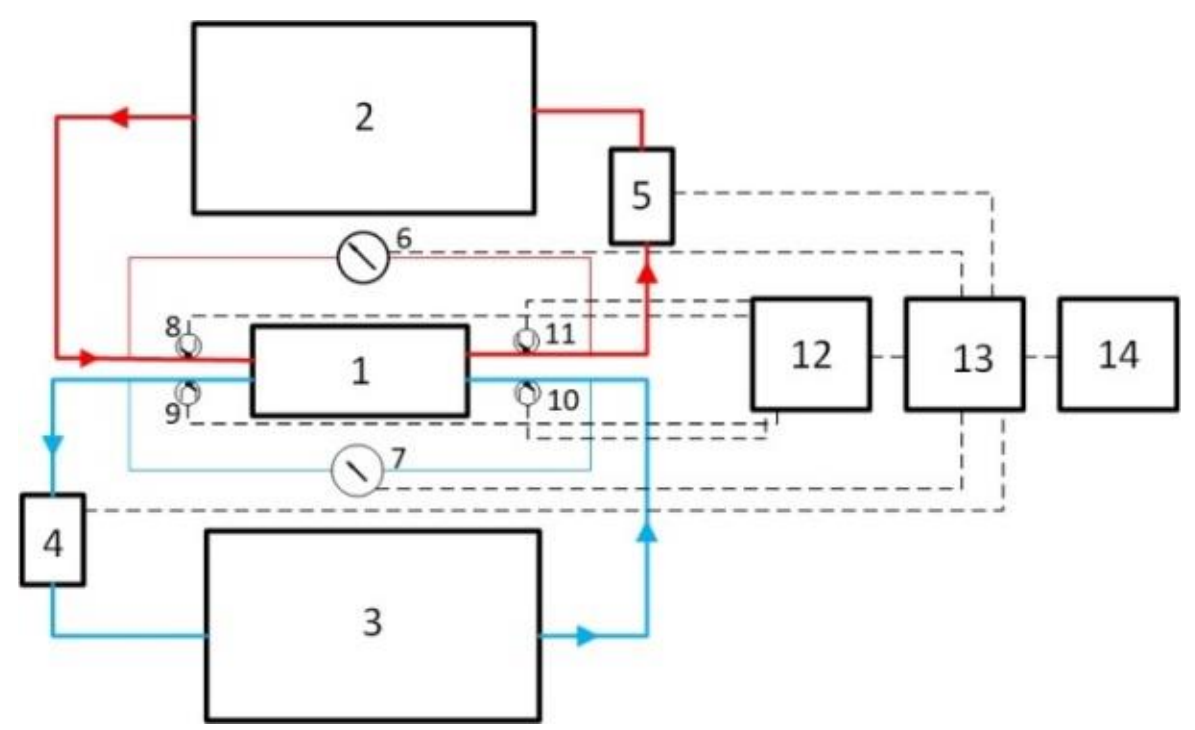

Fig. 4. The schematic diagram of the experimental facility; 1- the investigated minichannel heat exchanger, 2- hot side calibration bath, 3- cold side calibration bath, 4- cold side flow meter, 5- hot side flow meter, 6- hot side pressure transducer, 7- cold side pressure transducer, 8- hot side inlet temperature, 9- cold side outlet temperature, 10- cold side inlet temperature, 11- hot side outlet temperature, 12- ice point reference temperature, 13- digital multimeter, 14- data acquisition system

Tab. 1. Measurement accuracy in thermal balance method

\begin{tabular}{ll}
$\begin{array}{l}\text { Pressure } \\
\text { measurements }\end{array}$ & $\pm 0.05 \%$ of measurement range \\
\hline $\begin{array}{l}\text { Flow rate } \\
\text { measurements }\end{array}$ & $\pm 0.35 \%$ of measured value \\
\hline $\begin{array}{l}\text { Temperature } \\
\text { measurements }\end{array}$ & $\pm 0.25^{\circ} \mathrm{C}$ \\
\hline
\end{tabular}

\section{RESULTS AND DISCUSSION}

\subsection{Limiting current method}

The preliminary measurements carried out on the designed test facility with minichannel heat exchanger, aimed to present the variation in ion concentration along the minichannel length and the ion concentration in the working electrolyte. Therefore, the measurements for different values of bulk ion concentration has been performed.

The results of variation in ion concentration along the minichannel length are presented in Fig.5. It can be seen that major differences occur for lower Reynolds numbers. Therefore, the deviations of $C_{b}$ should be considered in calculations.

The reduction of dimensionless mass transfer coefficient (Sherwood number) with the increase in ion concentration is presented in Fig.6. The value of Sherwood number stabilizes when the bulk ion concentration reaches about $0,015 \mathrm{kmol} / \mathrm{m}^{3}$. Therefore, further investigations should be carried out at $C_{b}$ equal to around $0,02 \mathrm{kmol} / \mathrm{m}^{3}$.

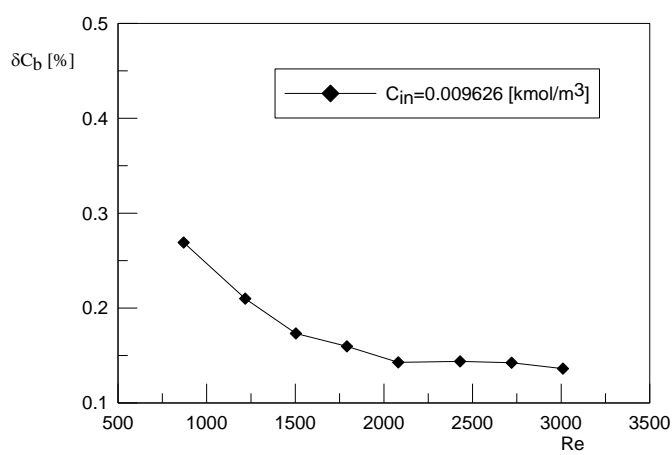

Fig. 5. Mean deviation in ion concentration along the minichannel length

The reduction in mass transfer coefficient with the increase of ion concentration at the same electrolyte flow rate has been observed. This situation can be explained by the smaller than the expected area of the cathode. The entire inner surface of the minichannel is supposed to be the cathode and this surface is included in equation (8) for mass transfer coefficient calculations. However, it may happen that only part of it will fulfil the task. This can occur if the ion concentration of the working electrolyte is too low. The reduction process at the cathode surface under convective-diffusion controlled conditions causes the reduction of the bulk ion concentration. If the concentration approaches zero before the end of the minichannel, the actual surface of the cathode is unknown. It is lower than the inner surface of the minichannel. In this case values of mass transfer coefficient received from equation (8) will be false. 


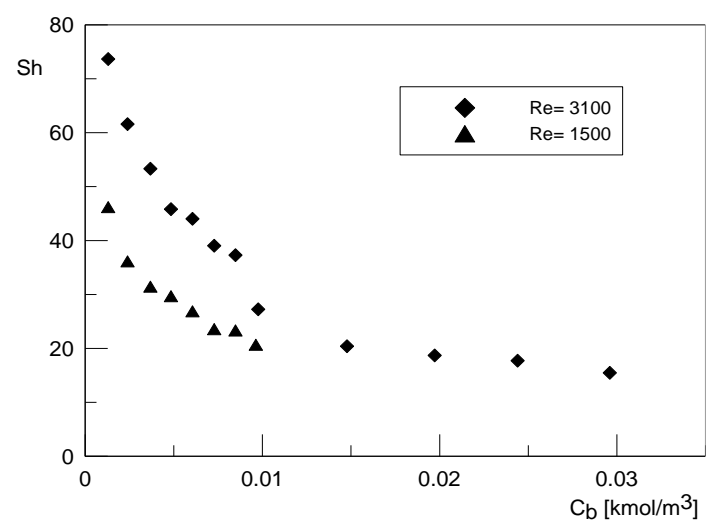

Fig. 6. Dependence of dimensionless mass transfer coefficient on concentration of reacting ions

\subsection{Thermal balance method}

The validation of the experimental facility adjusted to investigation of minichannel heat exchangers by thermal balance method has been established by comparing the measured heat transfer rate of cold and hot side of the minichannel heat exchanger.

The result of preliminary thermal measurements is presented in Fig. 7. The equation (13) was used to determine the heat transfer rate of hot and cold side $\dot{Q}_{h}$ and $\dot{Q}_{c}$ respectively. The measurements have been carried out for the water flow rate ranged from 0,25 to $1,15 \mathrm{l} / \mathrm{min}$. The temperature of the hot side was established to $70^{\circ} \mathrm{C}$, while the temperature of the cold side was maintained at $20^{\circ} \mathrm{C}$. The maximum obtained heat transfer rate was around $700 \mathrm{~W}$.

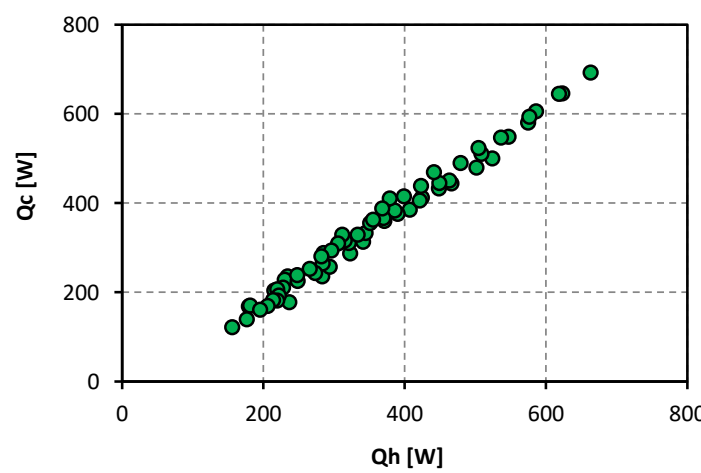

Fig. 7. The thermal balance of investigated minichannel heat exchanger

The obtained thermal balance showed that heat released on the hot side and heat absorbed by the cold side are almost equal across the measurement range and thermal equilibrium is reached. Therefore, investigated experimental facility is sufficiently insulated and there is no heat loss to ambience.

\section{CONCLUSIONS}

The main objective of the present paper was to present and describe research methods commonly applicable to determine thermal characteristics of minichannel heat exchangers. In general thermal performance of heat exchangers is obtained experimentally by thermal balance method. However, due to practical difficulties concerning experimental measurements of temperature or heat flux in small diameter channels, alternative techniques can be used. Among many other available methods, the limiting current technique have been emphasized The theoretical background of the limiting current method have been presented in details. Preliminary thermal measurements of a compact minichannel heat exchanger have been carried out on specially designed experimental test facility, in which the limiting current technique was applied. The investigated minichannel test section had $100 \mathrm{~mm}$ length straight channels with square cross section and hydraulic diameter of $2 \mathrm{~mm}$.

The geometrically analogical model of a minichannel heat exchanger was also investigated experimentally by means of classical thermal balance method. Therefore an experimental test facility was also designed in which the thermal balance method was applied. Preliminary measurements of thermal parameters have been carried out in order to validate the designed test facility. The design concept of the thermal balance test facility does not assume the possibility of direct measurement of the channel wall temperature, therefore the direct experimental determination of heat exchanger thermal characteristics was not possible. For this purpose, in further perspective the statistical method based on Wilson plot method will be applied in order to determine thermal characteristics of investigated heat exchanger. The obtained heat balance proved that there is no heat loss to ambience.

The forthcoming research include the complement of studies of minichannel heat exchanger with statistically determined thermal characteristics. It is also planned to extend the range of investigated minichannel heat exchangers to various channel geometries and cross sections by both the limiting current technique and thermal balance method.

\section{NOMENCLATURE}

\section{Symbols}

A - surface area of the cathode $\left[\mathrm{m}^{2}\right]$,

a - thermal diffusivity $\left[\mathrm{m}^{2} / \mathrm{s}\right]$,

$C_{b} \quad$ - bulk ion concentration $\left[\mathrm{kmol} / \mathrm{m}^{3}\right]$,

$C_{i n} \quad-$ ion concentration at the minichannel inlet $\left[\mathrm{kmol} / \mathrm{m}^{3}\right]$,

$C_{\text {out }}, \quad$ - ion concentration at the minichannel outlet $\left[\mathrm{kmol} / \mathrm{m}^{3}\right]$,

$C_{w} \quad$ - ion concentration at the electrode surface $\left[\mathrm{kmol} / \mathrm{m}^{3}\right]$, 
$c_{w} \quad-$ water specific heat $[\mathrm{J} /(\mathrm{kg} \cdot \mathrm{K})]$,

D - diffusion coefficient $\left[\mathrm{m}^{2} / \mathrm{s}\right]$,

$d_{H} \quad$ - hydraulic diameter $[\mathrm{m}]$

$F \quad$ - Faraday constant [As/kmol],

$h \quad-$ heat transfer coefficient $\left[\mathrm{W} /\left(\mathrm{m}^{2} \mathrm{~K}\right)\right]$,

$h_{D} \quad$ - mass transfer coefficient [m/s],

I - current in the circuit [A],

$I_{p} \quad-$ limiting current $[\mathrm{A}]$,

$i \quad-$ current density $\left[\mathrm{A} / \mathrm{m}^{2}\right]$,

$k-$ thermal conductivity $[\mathrm{W} /(\mathrm{mK})]$,

$N-$ molar lux density $\left[\mathrm{kmol} /\left(\mathrm{m}^{2} \mathrm{~s}\right)\right]$,

$\mathrm{Nu} \quad$ - Nusselt number,

$n-$ number of electrons consumed in electrode reaction,

$\operatorname{Pr} \quad$ - Prandtl number

Re - Reynolds number,

Sc - Schmidt number,

Sh - Sherwood number,

$T_{\text {avg }}$ - average water temperature,

$T_{\text {in }} \quad$ - inlet temperature [K],

$T_{\text {out }} \quad$ - outlet temperature [K],

$T_{S} \quad$ - wall surface temperature $[\mathrm{K}]$,

$T_{\infty} \quad-$ mean fluid bulk temperature $[\mathrm{K}]$,

$\dot{V}_{w} \quad-$ water flow rate $\left[\mathrm{m}^{3} / \mathrm{s}\right]$,

$\dot{V} \quad-$ volumetric flow rate of the electrolyte $\left[\mathrm{m}^{3} / \mathrm{s}\right]$

$q^{\prime \prime} \quad-$ heat flux $\left[\mathrm{W} / \mathrm{m}^{2}\right]$

$c, p, q$ - empirical constants,

\section{Greek letters}

$\rho \quad-$ water density $\left[\mathrm{kg} / \mathrm{m}^{3}\right]$,

$v-$ kinematic viscosity, $\left[\mathrm{m}^{2} / \mathrm{s}\right]$,

\section{References}

1. Owhaib W., Palm B. (2004). Experimental investigation of single-phase convective heat transfer in circular microchannels. Experimental Thermal and Fluid Science Vol. 28, pp. 105-110

2. Adams T.M., Abdel-Khalik S.I., Jeter S.M., Quresi Z.H. (1998). An experimental investigation of single-phase forced convection in microchannels. International Journal of Heat and Mass Transfer, Vol 41, pp. 851-857

3. Lelea D., Nishio S., Takano K. (2004). The experimental research on microtube heat transfer and fluid flow of distilled water. International Journal of Heat and Mass Transfer, Vol. 47, pp. 2817-2830

4. Yang C.-Y, Lin T.-Y. (2007). Heat transfer characteristics of water flow in microtubes. Experimental Thermal and Fluid Science, Vol. 32, pp. 432-439

5. Celata G.P., Cumo M., Marconi V., McPhail S.J., Zummo G. (2006). Microtube liquid single-phase heat transfer in laminar flow. International Journal of Heat and Mass Transfer, Vol. 49, pp. 3538-3546

6. Morini G.L. (2019). The challenge to measure singlephase convective heat transfer coefficients in microchannels. Heat Transfer Engineering, Vol. 40, No. 9-10, pp. 695-710

7. Wilk J. (2012). Convective mass/heat transfer in the entrance region of the short circular minichannel. Experimental Thermal and Fluid Science, Vol. 38, pp. 107-114

8. Wilk J. (2014). A review of measurements of the mass transfer in minichannels using the limiting current technique, Experimental Thermal and Fluid Science, Vol. 57, pp. 242-249
9. Wilk J. (2020). Heat/mass transfer analogy in the case of convective fluid flow through minichannels, International Journal of Thermal Sciences, Vol. 156, 106467

10. E. van Rooyen, M. Christians, J.R. Thome (2012). Modified Wilson Plots for Enchanced Heat Transfer Experiments: Current Status and Future Perspectives. Heat Transfer Engineering, 33:4-5, pp. 342-355

11. Fernàndez-Saera J., Uhía F.J., Sieres J., Campo A. (2007). A general review of the Wilson plot method and its modifications to determine convection coefficients in heat exchange devices. Applied Thermal Engineering, Vol. 27, pp. 2745-2757

12. Wilson E.E. (1915). A basis for rational design of heat transfer apparatus. Trans ASME J Heat Transfer, Vol. 37 , pp. 546-551

13. Rose J.W. (2004). Heat transfer coefficients, Wilson plots and accuracy of thermal measurements. Experimental Thermal and Fluid Science, Vol. 28, pp. 77-86

14. Rybiński W., Mikielewicz J. (2018). Statistical method for the determination of the minichannel hest exchanger's thermal characteristics. Energy, Vol. 158, pp. 139-147

15. Moreira T.A., Colmanetti A.R.A., Tibiriçà C.B. (2019). Heat transfer coefficient: a review of measurement techniques. Journal of the Brazilian Society of Mechanical Sciences and Engineering, Vol. 41, pp. 264289

16. Eckert E.R.G., Sakamoto H., Simon T.W. (2001). The heat/mass transfer analogy factor, $\mathrm{Nu} / \mathrm{Sh}$, for boundary layers on turbine blade profiles. International Journal of Heat and Mass Transfer, Vol. 44, , pp. 1223-1233.

17. Bard A.J., Faulkner L.R. (2005) Electrochemical methods. John Wiley \& Sons.

18. Wilk J., Grosicki S. (2018). Experimental study of electrochemical mass transfer in an annular duct with the electrolyte nanofluid. International Journal of Thermal Sciences, Vol. 129, pp.280-289.

19. Tychanicz-Kwiecień M., Gil P., Smusz R. (2019). The design of experimental set-up for testing of heat exchangers. Contemporary Issues of Heat and Mass Transfer, XV Symposium on Heat and Mass Transfer 2019 (SOHAMT 2019) 16-19.09.2019, Kołobrzeg, Poland pp.1-18,

20. Kell G.S. (1975). Density, Thermal Expansivity and Compressibility of Liquid Water from $0^{\circ} \mathrm{C}$ to $150^{\circ} \mathrm{C}$ : Correlations and Tables for Atmospheric Pressure and Saturation Reviewed and Expressed on 1968 Temperature Scale, Journal of Chemical and Engineering Data, Vol. 20, No. 1. 


\section{Biographical notes}

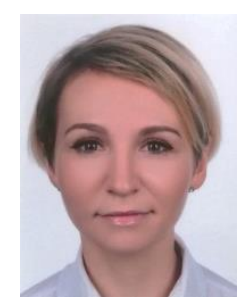

Maria Tychanicz-Kwiecień received her M.Sc. degree in Mechanics and Machine Design from Rzeszów University of Technology in 2015. Since 2015 she works as an assistant in the Department of Thermodynamics at the Rzeszów University of Technology. Her scientific interests focus on problems concerning heat transfer in minichannels. She has participated in 2 international and 7 national conferences. She is also a co-author of 9 scientific papers, including 2 of international range and 4 conference papers.

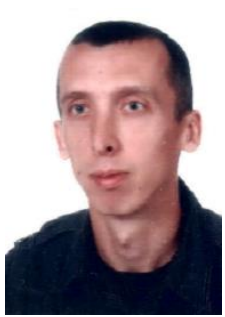

Sebastian Grosicki received his M.Sc. degree in Materials Engineering on the Faculty of Chemistry Rzeszów University of Technology. He completed his M.Sc. thesis at the Department of Plastics Technology, where in 2005 he started working as a technologist. Since 2011 he has been an assistant at the Faculty of Mechanical Engineering and Aviation at the Rzeszów University of Technology, where he is currently conducting research related to his $\mathrm{PhD}$ thesis at the Department of Thermodynamics. His scientific interests are focused on electrochemical methods in determining the mass/heat transfer coefficients and the application of nanofluids in enhancement of mass/heat transfer processes. 
